\title{
Crystal structure of dicaesium oxopentachloromolybdate(V), $\mathrm{Cs}_{2}\left(\mathrm{MoOCl}_{5}\right)$
}

\author{
J.-X. Mi ${ }^{\mathrm{I}}$ X.-C. Feng ${ }^{\mathrm{I}}$, H. Zhang ${ }^{\mathrm{II}}$, S.-Y. Mao ${ }^{\mathrm{I}}$ and J.-T. Zhao*III \\ 1 Xiamen University, College of Chemistry and Chemical Engineering, Xiamen, 361005 P. R. China \\ 11 Max-Planck-Institut für Chemische Physik fester Stoffe, Nöthnitzer Straße 40, D-01187 Dresden, Germany \\ III Chinese Academy of Sciences, Shanghai Institute of Ceramics, State Key Laboratory of High Performance Ceramics and Superfine Microstructure, 1295 \\ Dingxi Road, Shanghai, 200050 P. R. China
}

Received May 2, 2003, accepted and available on-line July 29, 2003; CSD-No. 409710
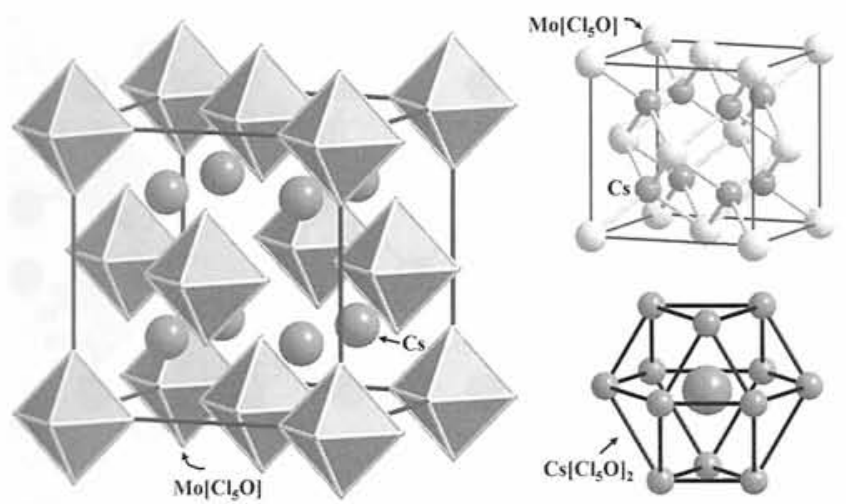

Abstract

$\mathrm{Cl}_{5} \mathrm{Cs}_{2} \mathrm{MoO}$, cubic, $F m \overline{3} m$ (No. 225$), a=10.2276(2) \AA$, $V=1069.8 \AA^{3}, Z=4, R_{\mathrm{gt}}(F)=0.027, w R_{\mathrm{ref}}\left(F^{2}\right)=0.058, T=295 \mathrm{~K}$.

\section{Source of material}

The title compound was synthesized in aqueous solution. The reaction was carried out with the mixture of $\mathrm{MoCl}_{5}(4.098 \mathrm{~g})$, $\mathrm{Cs}(\mathrm{OH}) \cdot \mathrm{H}_{2} \mathrm{O}(3.358 \mathrm{~g})$ and $30 \mathrm{ml} 37 \% \mathrm{HCl}$ with molar ratio of Mo: Cs $=3: 4$. The mixture was heated on the electric stove to boiling point while it was stirring. After it was cooled down and evaporated in air for several days, two kinds of crystals were obtained. One in the shape of octahedron with dark green corresponded to the title compound and was used in structure determination. The composition of formula was confirmed by chemical analysis (ICP) with Cs : Mo : $\mathrm{O}=2.20(6): 1.00(9): 0.8(2)$.

\section{Discussion}

The title compound was first synthesized by Brown [1]. But its structure was not reported yet until now. The crystal structure of the title compound is isotypic to $\mathrm{Cs}_{2}\left(\mathrm{NbOCl}_{5}\right)$. It is characterized by isolated $\left[\mathrm{MoCl}_{5} \mathrm{O}\right]$ octahedra linking caesium cations with chlorine or oxygen anions to form a three-dimensional structure. The title com-

pound has some common structural characteristics with typical structure of $\mathrm{CaF}_{2}$ which have same space group $(F m \overline{3} m)$ with it. Its crystal structure can be deduced from fluorite structure. $\left[\mathrm{MoCl}_{5} \mathrm{O}\right.$ ] octahedra locate at every corner and face-center sites of the cubic cell as calcium $\left(\mathrm{Ca}^{2+}\right)$ cations in the fluorite structure. Caesium cations occupy all of eight subcells (which have half of cubic cell edge) body-center sites as fluorine (F) anions do in the fluorite structure. The structure can be understood as $\left[\mathrm{MoCl}_{5} \mathrm{O}\right]$ close-packing in face-centered cubic (fcc) and caseium filling its all tetrahedra holes (see the topological drawing in the right upper of the figure). Each caesium cation is linked with four $\left[\mathrm{MoCl}_{5} \mathrm{O}\right]$ octahedra by 12 chlorine or oxygen anions with bond distance $(\mathrm{Cs}-\mathrm{Cl}(\mathrm{O}))$ of $3.622 \AA$, so its coordination number is 12 (see the caesium coordination polyhedron in the bottom of the figure). Each $\left[\mathrm{MoCl}_{5} \mathrm{O}\right]$ octahedron is linked with 8 caesium cations in cubic shape. The bond distance of $\mathrm{Mo}-\mathrm{Cl}(\mathrm{O})$ in $\left[\mathrm{MoCl}_{5} \mathrm{O}\right]$ octahedron is $2.346 \AA$. Chlorine and oxygen anions are of disorder in the structure and occupy in the same equational positions. Caesium's ionic radius is larger than potassium's, so its structure is different from $\mathrm{K}_{2}\left(\mathrm{MoOCl}_{5}\right)$ in which chlorine and oxygen anions are of order and occupy their own positions [2]. For this cause, the title compound has higher symmetry in structure than $\mathrm{K}_{2}\left(\mathrm{MoOCl}_{5}\right)$ does.

Table 1. Data collection and handling.

\section{Crystal:}

Wavelength:

$\mu$ :

Diffractometer, scan mode: $2 \theta_{\max }$ :

$N(h k l)_{\text {measured }}, N(h k l)_{\text {unique: }}$

Criterion for $I_{\mathrm{obs}}, N(h k l)_{\mathrm{gt}}$ :

$N(\text { param })_{\text {refined: }}$

Programs:

\author{
dark green octahedron, \\ size $0.08 \times 0.08 \times 0.08 \mathrm{~mm}$ \\ Mo $K_{\alpha}$ radiation $(0.71073 \AA)$ \\ $91.16 \mathrm{~cm}^{-1}$ \\ Rigaku R-axis RAPID, $\omega / \varphi$ \\ $72.26^{\circ}$ \\ 225,166 \\ $I_{\mathrm{obs}}>2 \sigma\left(I_{\mathrm{obs}}\right), 120$ \\ 7 \\ SHELXL-97 [3], DIAMOND [4]
}

Table 2. Atomic coordinates and displacement parameters (in $\AA^{2}$ ).

\begin{tabular}{lllllllllll}
\hline Atom & Site & $x$ & $y$ & $z$ & $U_{11}$ & $U_{22}$ & $U_{33}$ & $U_{12}$ & $U_{13}$ & \\
$\mathrm{Cs}(1)$ & $8 c$ & $1 / 4$ & $1 / 4$ & $1 / 4$ & $0.0418(3)$ & $U_{11}$ & $U_{11}$ & 0 \\
$\mathrm{Mo}(1)$ & $4 a$ & 0 & 0 & 0 & $0.0661(7)$ & $U_{11}$ & $U_{11}$ & 0 & 0 \\
$\mathrm{Cl} / \mathrm{O}(1){ }^{a}$ & $24 e$ & 0 & $0.7707(2)$ & 0 & $0.0424(6)$ & $U_{11}$ & $U_{11}$ & 0 & 0 \\
\hline
\end{tabular}

a: $\mathrm{Cl} / \mathrm{O}(1)=0.83 \mathrm{Cl}+0.17 \mathrm{O}$

\footnotetext{
* Correspondence author (e-mail: jtzhao@mail.sic.ac.cn)
} 
Acknowledgments. This project was supported by the Fund for Distinguished Young Scholars from the NNSF of China, and Fund of the 863 project from the DOST of China. Thanks also go to Ms. U. Schmidt's for chemical analysis (MPI CPfS, Dresden).

\section{References}

1. Brown, D.: Some oxychloro-complexes of quinquevalent elements. J. Chem. Society (1964) 4944-4948.

2. Tkachev, V.V.; Krasochka, O. N.; Atovmyan, L. O.: On the Structure of the Crystals $\mathrm{K}\left(\mathrm{OsNBr}_{4} \mathrm{H}_{2} \mathrm{O}\right) \mathrm{H}_{2} \mathrm{O}$ and $\mathrm{K}_{2} \mathrm{MoOCl}_{5}$. Zh. Struktur. Khim. 17 (1976) $940-941$.
3. Sheldrick, G. M.: SHELXL-97. program for refining crystal structures. University of Göttingen, Germany 1997.

4. Brandenburg, K.: Diamond, Version 2.1e, Crystal Impact GbR, Bonn, Germany 1996-2001. 